\title{
Etiological Factors for First Single Early Pregnancy Loss: Are They Different from Recurrent Pregnancy Loss?
}

\author{
Papa Dasari ${ }^{1}$, Sonal Garg ${ }^{2}$, Rakhee Kar $^{3}$, Thyagaraju Chitra ${ }^{4} \odot$
}

\begin{abstract}
Aim and objective: The recommendation for investigation of pregnancy loss is to test only after two or more pregnancy losses. But in practice, we find women with single pregnancy loss seeking explanation. The purpose of this study was to determine the identifiable causes and their proportion in women with first early pregnancy loss and to compare with that of women with recurrent pregnancy loss (RPL).

Materials and methods: This cross-sectional analytical study was undertaken between 2018 and 2019. Group A included 105 women with first single pregnancy loss and group B included 105 women with RPL. The recommended investigations for etiological factors were done in both groups except karyotyping, and thrombophilia screening was done in those with unknown etiology.

Statistical analysis: Etiological factors were expressed as proportions, and comparison between two groups was done by unpaired $t$-test and Mann-Whitney test.

Results: Sociodemographic factors and gestational age were similar in both the groups. Significantly more number of women with first single pregnancy loss $(58 \%)$ had known etiological factors than women with RPL $(43 \%)(p=0.038)$. Endocrine causes were commonest in both the groups (first pregnancy loss $36 \%$ vs RPL $21 \% ; p=0.023$ ). Out of the women with unknown causes, $18 \%$ of women were positive for thrombophilia in each group and more than $50 \%$ of them were antiphospholipid antibodies (APLA) positive.

Conclusion: Significant proportion of women with single first pregnancy loss have treatable etiological factors like those of RPL. Hence evaluation should be undertaken to achieve optimum outcomes during the next pregnancy and prevent RPL.

Clinical significance: Evaluation of women with first pregnancy loss helps the clinician to prevent pregnancy loss in subsequent pregnancies by appropriate management as per the etiology.

Keywords: Endocrine cause, Etiology, First early pregnancy loss, Miscarriage, Recurrent pregnancy loss, Thrombophilia.

Journal of South Asian Federation of Obstetrics and Gynaecology (2021): 10.5005/jp-journals-10006-1944
\end{abstract}

\section{INTRODUCTION}

Pregnancy loss is a distressing condition for both the patient and obstetrician. It can occur at any gestational period but most commonly during early pregnancy. The etiologies for early pregnancy loss and late pregnancy loss are most often different. Early pregnancy loss is defined as a nonviable intrauterine pregnancy with either an empty gestational sac or a gestational sac containing an embryo or fetus without cardiac activity within the first $12+6 / 7$ weeks of gestation. In the first trimester, the terms miscarriage, spontaneous abortion, and early pregnancy loss are used interchangeably as there is no consensus on terminology in the literature.

Early pregnancy loss occurs in $10 \%$ of all clinically recognized pregnancies and approximately $80 \%$ of all cases of pregnancy losses occur within the first trimester. ${ }^{2}$ Pregnancy loss when occurs repeatedly is termed recurrent pregnancy loss (RPL). According to the European Society of Human Reproduction and Embryology (ESHRE), RPL is a distinct disorder defined by two or more failed clinical pregnancies. ${ }^{3}$ Guidelines recommend evaluation only for RPL as a wide variety of etiological factors have been described in the literature and evaluation of RPL revealed causes only in $50 \%$. But there are no recommendations for initiation of investigations after first or single pregnancy loss.

Whenever a woman suffers pregnancy loss, an explanation is sought for the same from the treating obstetrician. Sometimes women approach the clinicians after having suffered pregnancy loss and request for investigations, but the clinical practice recommendations are in place to investigate after two or more pregnancy losses and not for single pregnancy loss.

\begin{abstract}
1,2,4 Department of Obstetrics and Gynaecology, Jawaharlal Institute of Postgraduate Medical Education and Research, Puducherry, India

${ }^{3}$ Department of Pathology, Jawaharlal Institute of Postgraduate Medical Education and Research, Puducherry, India

Corresponding Author: Papa Dasari, Department of Obstetrics and Gynaecology, Jawaharlal Institute of Postgraduate Medical Education and Research, Puducherry, India, Phone: +91 9442566883, e-mail: dasaripapa@gmail.com

How to cite this article: Dasari P, Garg S, Kar R, et al. Etiological Factors for First Single Early Pregnancy Loss: Are They Different from Recurrent Pregnancy Loss? J South Asian Feder Obst Gynae 2021;13(4):259-264.

Source of support: Intramural fund from Jawaharlal Institute of Postgraduate Medical Education and Research

Conflict of interest: None
\end{abstract}

A significant proportion of women (20\%) who experience a miscarriage become symptomatic for depression and anxiety. ${ }^{5}$ This warrants diagnostic workup and interventions. There are no studies with regard to the initiation of investigations after first early pregnancy loss. In this context, this study aims to find out the etiological factors in women with first early pregnancy loss and to compare it with women who had two or more than two early pregnancy losses (RPL). This study will establish the need, if any, to investigate a woman after one pregnancy loss for possible etiological factors. This will also find out the common causes of early pregnancy loss in this population and ensure adequate

() The Author(s). 2021 Open Access This article is distributed under the terms of the Creative Commons Attribution 4.0 International License (https://creativecommons. org/licenses/by-nc/4.0/), which permits unrestricted use, distribution, and non-commercial reproduction in any medium, provided you give appropriate credit to the original author(s) and the source, provide a link to the Creative Commons license, and indicate if changes were made. The Creative Commons Public Domain Dedication waiver (http://creativecommons.org/publicdomain/zero/1.0/) applies to the data made available in this article, unless otherwise stated. 
timely intervention for treatable causes without waiting for the subsequent pregnancy loss.

\section{Materials and Methods}

\section{Study Design and Settings}

This cross-sectional analytical study was done in the Department of Obstetrics and Gynaecology, Jawaharlal Institute of Postgraduate Medical Education and Research (JIPMER), Puducherry, South India, between January 2018 and August 2019. Processing of various samples was done in the department of biochemistry glucose tolerance test and clinical immunology [antiphospholipid antibodies (APLA)], and pathology (protein C and protein S). Two groups of women with 105 subjects in each group were enrolled (group A-first early pregnancy loss; group B-RPL).

\section{Participants}

\section{Inclusion Criteria}

The inclusion criteria were as follows:

Group A-Pregnant women admitted with first early pregnancy loss (gestational age $\leq 14$ weeks) or nonpregnant women attending outpatient department (OPD) with history of one early pregnancy loss and requesting investigations for pregnancy loss.

Group B-Women with two or more than two early pregnancy losses (RPL).

\section{Exclusion Criteria}

The exclusion criteria were age $<18$ years and $>35$ years, prior live birth, known cases of hypertension, diabetes mellitus (DM), hypothyroidism, and autoimmune disorders.

\section{Sample Size Calculation}

The sample size was calculated using OpenEpi software version 3.0 using $95 \%$ confidence level $(\mathrm{Cl})$ and power of $80 \%$. As there were no prior studies on single early pregnancy loss we assumed that the difference in proportion of identifiable causes in two groups that is women with two or more than two pregnancy losses (RPL) and women with first early pregnancy loss to be $20 \%$. The proportion of identifiable causes is $50 \%$ among women in RPL. ${ }^{4}$ The proportion of identifiable causes in group A is $30 \%$, the sample size was 95 in each group, and with $10 \%$ dropouts, the final sample size was as follows: group A-105; group B-105. For sampling, purposive sampling technique was used.

\section{Study Procedure}

Women fulfilling the inclusion criteria were explained about the protocol of the study and a written informed consent was taken from each participant enrolled in the study. The enrolled participants were divided into two groups: group A - women with first early pregnancy loss and group B-women with two or more than two pregnancy losses (RPL). Demographic data including age, occupation, education, socioeconomic status were collected by interviewing the patient. Clinical profile including gravidity, parity, past obstetric history, family history, and treatment history was documented on a proforma after interviewing the patient and from the medical records. A general physical examination was carried out, and height, weight, and BMI were calculated. A complete systemic examination, including thyroid, breast, respiratory, cardiovascular, abdominal, and gynecological examination, was performed. Parameters noted in this study were age, BMI, socioeconomic status, number of pregnancy losses, clinical assessment to find out the cause of pregnancy loss, thyroid function test, $75 \mathrm{~g}$ oral glucose tolerance test, urine culture sensitivity, cervical swab culture sensitivity, ultrasonogram to assess uterine anomalies, fetus assessment, and polycystic ovary syndrome (PCOS). If no cause was found, thrombophilia profile for acquired thrombophilias and congenital thrombophilias (lupus anticoagulant; $\beta 2$ glycoprotein antibodies; IgM and IgG, anticardiolipin antibodies, IgM and IgG; and protein $\mathrm{C}$ and protein $\mathrm{S}$ ) was done. Investigation for protein $\mathrm{C}$ and protein $\mathrm{S}$ deficiency was done 6 weeks after pregnancy loss to avoid false negatives during pregnancy.

Primary outcome measures were proportion of women with identifiable causes for first early pregnancy loss and RPL.

Secondary outcome measures were proportion of women with various etiological factors.

\section{Statistical Analysis}

Data were collected and entered into statistical software SPSS version 15. Continuous variables like height, weight, age, BMI, and hormonal levels were expressed as mean (standard deviation) or median (interquartile range) as per distribution of data and compared across two groups using unpaired $t$-test (normal/parametric distribution) or Mann-Whitney test (nonparametric distribution). Categorical variables (outcome) like proportion of women with endocrine causes and other nonendocrine causes were described as frequency and proportions and compared between groups by Chi-square test. A $p$ value $<0.05$ was considered as significant.

\section{Results}

One hundred and five patients were recruited in group A (pregnant women admitted with first early pregnancy loss or nonpregnant women attending OPD with history of one pregnancy loss) and 105 patients were recruited in group $B$ with RPL. Four women in group $A$ (first pregnancy loss) and two women in group $B$ (RPL) were in nonpregnant state, rest of the women were recruited immediately after pregnancy loss as inpatients.

The demographic profile of subjects is shown in Table 1. The mean age of women with first early pregnancy loss (group A) was $25 \pm 4.2$ years and mean BMI was $22 \mathrm{~kg} / \mathrm{m}^{2}$. Seventy-three percent of women with first pregnancy loss had normal weight, $21 \%$ were preobese, and only one woman was obese (class I). Majority of patients belonged to class III and IV Kuppuswamy socioeconomic status classification (34 and 67\%, respectively). The mean gestational age at pregnancy loss in group A was 10 weeks. There was no statistically significant difference of age, BMI, socioeconomic status, and gestational age at pregnancy loss between women in both the groups.

Table 2 shows the comparison of causes of first pregnancy loss with that of RPL. The proportion of known causes in group A women with single pregnancy loss was $58 \%$ as compared to $43 \%$ in group B (women with RPL) and the difference was statistically significant. Endocrine causes were the commonest in both the groups, and the proportion of endocrine causes in first pregnancy loss (36\%) was significantly more than RPL group (21\%) with $p=0.023$. Combined etiology was the second commonest (group A $15.23 \%$ vs group $B$ $19 \% ; p=0.46)$. The percentage of anatomical, infectious, and combined causes was similar between both the groups.

Thrombophilia evaluation was done for unknown causes (103) in both the groups (group A-44 and group B-59). Eighteen percent of women in each group were positive for thrombophilia with $p$ value of 0.47 . Thus, the proportion of thrombophilia-positive women in both the groups was similar (Table 3). Of the acquired 
Table 1: Comparison of sociodemographic and clinical profile

\begin{tabular}{|c|c|c|c|c|}
\hline Sl. No & Parameter & $\begin{array}{c}\text { Group A } \\
N(\%)\end{array}$ & $\begin{array}{c}\text { Group B } \\
N(\%)\end{array}$ & pvalue \\
\hline 1 & Mean age (years) $\pm S D$ & $25.1 \pm 4.26$ & $25.9 \pm 4.21$ & 0.17 \\
\hline 2 & Mean BMI $\left(\mathrm{kg} / \mathrm{m}^{2}\right) \pm \mathrm{SD}$ & $22.74 \pm 2.84$ & $23 \pm 3.16$ & 0.68 \\
\hline 3 & $\begin{array}{l}\text { BMI }\left(\mathrm{kg} / \mathrm{m}^{2}\right) \\
\text { Underweight }(<18.5) \\
\text { Normal weight }(18.5-24.9) \\
\text { Pre-obesity }(25-29.9) \\
\text { Obesity class I }(30-34.9)\end{array}$ & $\begin{array}{c}4(3.8 \%) \\
77(73.3 \%) \\
23(21.9 \%) \\
1(1 \%)\end{array}$ & $\begin{array}{c}4(3.8 \%) \\
75(71.4 \%) \\
22(21 \%) \\
4(3.8 \%)\end{array}$ & 0.584 \\
\hline 4 & $\begin{array}{l}\text { Socioeconomic status (Kuppuswamy classification) } \\
\text { Class I } \\
\text { Class II } \\
\text { Class III } \\
\text { Class IV }\end{array}$ & $\begin{array}{c}- \\
3(3.5 \%) \\
29(34.5 \%) \\
73(67 \%)\end{array}$ & $\begin{array}{c}- \\
4(3.8 \%) \\
40(38.1 \%) \\
61(58.1 \%)\end{array}$ & 0.226 \\
\hline 5 & Mean gestational age at pregnancy loss (weeks) \pm SD & $10.3 \pm 1.9$ & $10.23 \pm 2.1$ & 0.49 \\
\hline
\end{tabular}

${ }^{*} p$ value was calculated using independent Student $t$-test for age, BMI, and gestational age and Chi-square test for BMI classification and socioeconomic status

Table 2: Comparison of etiological factors: first early pregnancy loss vs recurrent pregnancy loss

\begin{tabular}{|c|c|c|c|c|}
\hline SI. No & Etiological factors & $\begin{array}{c}\text { Group A } \\
N(\%)\end{array}$ & $\begin{array}{c}\text { Group B } \\
N(\%)\end{array}$ & $p$ value \\
\hline 1 & Unknown & $44(41.90 \%)$ & $59(56.19 \%)$ & 0.038 \\
\hline 2 & Known & $61(58.09 \%)$ & $46(43.80 \%)$ & \\
\hline \multirow[t]{4}{*}{ A } & Anatomical factors & $5(4.76 \%)$ & $2(1.90 \%)$ & 0.249 \\
\hline & Uterine anomaly & $3(2.9 \%)$ & $1(0.95 \%)$ & \\
\hline & Fibroid & $2(1.9 \%)$ & 0 & \\
\hline & Cervical incompetence & - & $1(0.95 \%)$ & \\
\hline B & Fetal anomaly & 0 & & \\
\hline \multirow[t]{5}{*}{ C } & Endocrine & $38(36.19 \%)$ & $23(21.90 \%)$ & 0.023 \\
\hline & Hypothyroidism & $9(8.6 \%)$ & $5(4.8 \%)$ & \\
\hline & Type 2 diabetes mellitus (T2DM) & $8(7.6 \%)$ & $5(4.8 \%)$ & \\
\hline & Polycystic ovary syndrome (PCOS) & $6(5.7 \%)$ & $1(0.95 \%)$ & \\
\hline & Gestational diabetes mellitus (GDM) & $15(14.28 \%)$ & $12(11.42 \%)$ & \\
\hline D & Infections & $2(1.9 \%)$ & $1(0.95 \%)$ & 0.48 \\
\hline \multirow[t]{12}{*}{$\mathrm{E}$} & Combined etiology & $16(15.23 \%)$ & $20(19.04 \%)$ & 0.464 \\
\hline & $\mathrm{GDM}+\mathrm{PCOS}$ & 0 & $1(\%)$ & \\
\hline & GDM + hypothyroidism & $3(2.9 \%)$ & $7(6.7 \%)$ & \\
\hline & GDM + PCOS + hypothyroidism & 0 & $1(0.95 \%)$ & \\
\hline & GDM + cervicovaginal infections & $4(3.80 \%)$ & $3(2.9 \%)$ & \\
\hline & T2DM + hypothyroidism & $5(4.8 \%)$ & $3(2.9 \%)$ & \\
\hline & $\mathrm{T} 2 \mathrm{DM}+\mathrm{PCOS}$ & $3(2.9 \%)$ & 0 & \\
\hline & Uterine anomalies + hypothyroid & $1(1 \%)$ & $1(0.95 \%)$ & \\
\hline & Uterine anomalies + PCOS & 0 & $1(0.95 \%)$ & \\
\hline & Cervical incompetence + GDM & 0 & $1(0.95 \%)$ & \\
\hline & Cervical incompetence + hypothyroid + PCOS & 0 & $1(0.95 \%)$ & \\
\hline & Lupus anticoagulant + hypothyroid & 0 & $1(0.95 \%)$ & \\
\hline
\end{tabular}

" $p$ value was calculated using Chi-square test for known, endocrine, infections, and combined causes and Fischer exact test for anatomical causes

thrombophilias, more than $50 \%$ were APLA positive in both the groups.

When thrombophilia evaluation was considered to be a known cause for pregnancy loss, in women with first pregnancy loss, the proportion of known causes increased from 58 to $65 \%$ and 43 to $54 \%$ in the RPL group. The proportion of identifiable causes in both the groups was similar after addition of thrombophilia evaluation (group A 65\% vs group B 54\%; $p=0.09$ ) (Table 4A).
Antiphospholipid antibodies examination was done for all the women with unknown causes (44 in group A and 59 in group B). Beta-2 glycoprotein was positive only in one woman in group $B$, and anticardiolipin antibodies were positive in three women in group $A$ and four women in group B. Lupus anticoagulant was positive in three women in group A and six women in group B. As congenital thrombophilia screening being costly and because of limited funds, it was performed for 23 women with first pregnancy loss and 27 women 
with RPL. Protein S deficiency was present in four women in group A and five in group B (Table 4B). There was no significant difference between both groups.

\section{Discussion}

The present study was a descriptive, analytical study to know the etiology of first early pregnancy loss and to compare the proportion of identifiable causes between first early pregnancy loss and RPL. The study included 105 women in group A (first early

Table 3: Comparison of thrombophilia evaluation

\begin{tabular}{|c|c|c|c|c|}
\hline SI. No & $\begin{array}{l}\text { Thrombophilia } \\
\text { evaluation }\end{array}$ & $\begin{array}{c}\text { Group A n (\%) } \\
\quad N=44\end{array}$ & $\begin{array}{c}\text { Group B n (\%) } \\
N=59\end{array}$ & $p$ value ${ }^{*}$ \\
\hline 1 & $\begin{array}{l}\text { Thrombophilia } \\
\text { negative }\end{array}$ & $36(81.81 \%)$ & 48 (81.35\%) & \\
\hline 2 & $\begin{array}{l}\text { Thrombophilia } \\
\text { positive }\end{array}$ & $8(18.18 \%)$ & 11 (18.64\%) & 0.47 \\
\hline \multirow[t]{3}{*}{ A } & APLA positive & $4(50 \%)$ & $6(54.5 \%)$ & NS \\
\hline & Primary & 4 & 5 & \\
\hline & Secondary & - & 1 & \\
\hline B & $\begin{array}{l}\text { Protein C } \\
\text { deficiency }\end{array}$ & - & 0 & \\
\hline C & $\begin{array}{l}\text { Protein S } \\
\text { deficiency }\end{array}$ & $3(37.5 \%)$ & $4(36.3 \%)$ & \\
\hline D & $\begin{array}{l}\text { APLA positive } \\
+ \text { protein S } \\
\text { deficiency }\end{array}$ & $1(12.5 \%)$ & 1 (9.09\%) & \\
\hline
\end{tabular}

Table 4A: Proportion of etiological factors with addition of thrombophilia evaluation

\begin{tabular}{llccc}
\hline \multicolumn{2}{l}{ Parameter studied } & $\begin{array}{c}\text { Group A } \\
N=105(\%)\end{array}$ & $\begin{array}{c}\text { Group B } \\
N=105(\%)\end{array}$ & p value \\
\hline $\begin{array}{l}\text { Excluding } \\
\text { thrombophilia } \\
\text { evaluation }\end{array}$ & $\begin{array}{l}\text { Known } \\
\text { etiology }\end{array}$ & $61(58.09 \%)$ & $46(43.80 \%)$ & 0.038 \\
$\begin{array}{l}\text { Unknown } \\
\text { etiology }\end{array}$ & $44(41.90 \%)$ & $59(56.19 \%)$ & \\
$\begin{array}{l}\text { Including } \\
\text { thrombophilia } \\
\text { evaluation }\end{array}$ & $\begin{array}{l}\text { Known } \\
\text { etiology }\end{array}$ & $69(65.17 \%)$ & $57(54.28 \%)$ & 0.09 \\
\hline${ }^{*}$ Unknown & $36(34.28 \%)$ & $48(45.71 \%)$ & \\
\hline
\end{tabular}

${ }^{*} p$ value was calculated using Chi-square test pregnancy loss) and another 105 in group B (RPL). We found that the proportion of identifiable causes in first early pregnancy loss was similar to that of RPL $(p=0.09)$. In $65 \%(n=69)$ of women in group A and $54 \%(n=57)$ women in group B, various etiological factors were identified.

There are no studies in the literature that evaluated causes for first early pregnancy loss. In the present study, about $40 \%$ of pregnancy loss both in first pregnancy loss and RPL group was found to be among the age-group of 21-25 years. A previous study by Nybo Anderson et al. showed that as the age increased, the percentage of RPL increased. ${ }^{6}$ We did not find a similar trend in the present study. The incidence of RPL in their study in the age-group of $40-44$ years was $51 \%$ as compared to $11 \%$ in $21-25$ years. We did not recruit women $>35$ years in our study because pregnancy loss occurs more commonly in this group and the number of pregnant women would be less for analysis. The most common age-group of antenatal women in our population is $21-25$ years, which might be the reason for finding the maximum incidence of RPL in this age-group.

Bhandari et al. in their study on obese women with RPL found that majority of women (48.6\%) had normal weight, 31\% were pre-obese, and $19 \%$ were obese. ${ }^{7}$ Matjila et al. in their study on medical conditions in RPL found that majority of the women were obese $(42 \%){ }^{8}$

Cavalcante et al. performed a meta-analysis on obesity and recurrent miscarriage and reported $47 \%$ of women with RPL in normal weight category, while $29 \%$ were pre-obese and $22 \%$ were class I obese. ${ }^{9}$ In our study also, similar to Bhandari et al. ${ }^{7}$ and meta-analysis by Cavalcante et al., ${ }^{9}$ majority of women had normal weight (71\%) and $21 \%$ women were pre-obese, which was comparable to previous studies, but only $3.8 \%$ women were obese, which was less as comparable to previous studies. The difference in the findings may be due to different population characteristics. Bhandari et al. performed their study in the UK and Matjila et al. on South African women. The incidence of obesity as such in India is less as compared to the west.

Based on previous studies, endocrine causes were the commonest among known causes of RPL. DM was found in $26 \%$ of women, ${ }^{10}$ hypothyroidism in $9-12 \%,{ }^{10,11}$ and PCOS in $7.8 \%$ of women with RPL. ${ }^{12}$ In the present study also, we found that endocrine causes (21.9\%) were commonest among RPL women which was comparable to previous study. ${ }^{13} \mathrm{DM}$, hypothyroidism, and PCOS comprised $16.2 \%, 4.8 \%$ and $0.95 \%$ respectively, in women with RPL in our study. The prevalence of hypothyroidism and diabetes was found to be higher in previous studies than the present study. The incidence of PCOS in RPL women was found to

Table 4B: Subgroup analysis: thrombophilia

\begin{tabular}{|c|c|c|c|c|c|c|}
\hline \multirow[b]{2}{*}{ Sl. No } & \multirow[b]{2}{*}{ Type of thrombophilia } & \multicolumn{2}{|r|}{ Group A } & \multicolumn{2}{|r|}{ Group B } & \multirow[b]{2}{*}{$p$ value } \\
\hline & & Number screened & Thrombophilia positive N(\%) & Number screened & Thrombophilia positive N (\%) & \\
\hline A & Acquired thrombophilia & 44 & 6 & 59 & 8 & \\
\hline 1 & Beta-2 glycoprotein antibody & 44 & 0 & 59 & $1(1.51 \%)$ & 1.00 \\
\hline 2 & Anticardiolipin antibody (ACLA) & 44 & $3^{*}(6.81 \%)$ & 59 & $3^{* *}(6.06 \%)$ & 1.00 \\
\hline 3 & Lupus anticoagulant (LAC) & 44 & $3(6.81 \%)$ & 59 & $4(9.09 \%)$ & 0.736 \\
\hline B & Congenital thrombophilia & 23 & 4 & 27 & 5 & \\
\hline 1 & Protein C deficiency & 23 & 0 & 27 & 0 & - \\
\hline 2 & Protein S deficiency & 23 & $4(17.39 \%)$ & 27 & $5(18.51 \%)$ & 1.00 \\
\hline
\end{tabular}

${ }^{*}$ Group A-one woman was both LAC and ACLA positive; One woman was LAC positive and also had protein S deficiency; ${ }^{* *}$ Group B-one woman was both LAC and ACLA positive; One woman was ACLA positive and also had protein S deficiency 
be $0.95 \%$ in our study. PCOS in RPL varied widely between 4.8 and $80 \%$ as described in the literature, so more studies are required to come to a consensus. ${ }^{14}$

Salim et al. found uterine anomalies in $5 \%$ of women with RPL, whereas in our study, it was only $0.95 \% .{ }^{15}$ Infections as an etiological factor were found to be less $(0.95 \%)$, which was comparable to previous studies in the literature. ${ }^{16}$ In the present study, $19 \%$ of women had combined etiology and only one study in the literature by Lee et al. has reported combined etiology (48\%) contributing to $\mathrm{RPL}$, but the authors did not clarify causes included in the combined etiology. ${ }^{11}$

Similar to the previous studies, in $56 \%$ of women with RPL, the cause of RPL was unknown. ${ }^{4}$

There are no studies to find out the etiology of first early pregnancy loss. The various etiological factors found in the present study for first early pregnancy loss are shown in Figure 1. Endocrine causes were significantly higher in first pregnancy loss than RPL. The proportion of other causes was similar to RPL. We found that the proportion of identifiable causes in first early pregnancy loss was more than that of RPL, which was an unanticipated finding as there are no studies or recommendations for evaluation of first pregnancy loss in the literature so far.

Previous study by Vora et al. showed that in women with unknown causes of RPL, 75\% were thrombophilia positive. Forty-six percent were positive for acquired thrombophilia and 37\% were positive for congenital thrombophilia (Table 5). They screened for lupus anticoagulant, anticardiolipin antibodies, B2 glycoprotein 1 antibody, annexin $\mathrm{V}$, protein $\mathrm{C}$, protein $\mathrm{S}$, antithrombin III, factor $\mathrm{V}$ Leiden, PT gene G20210A, MTHFR C677T, EPCR 23 bp insertion, and

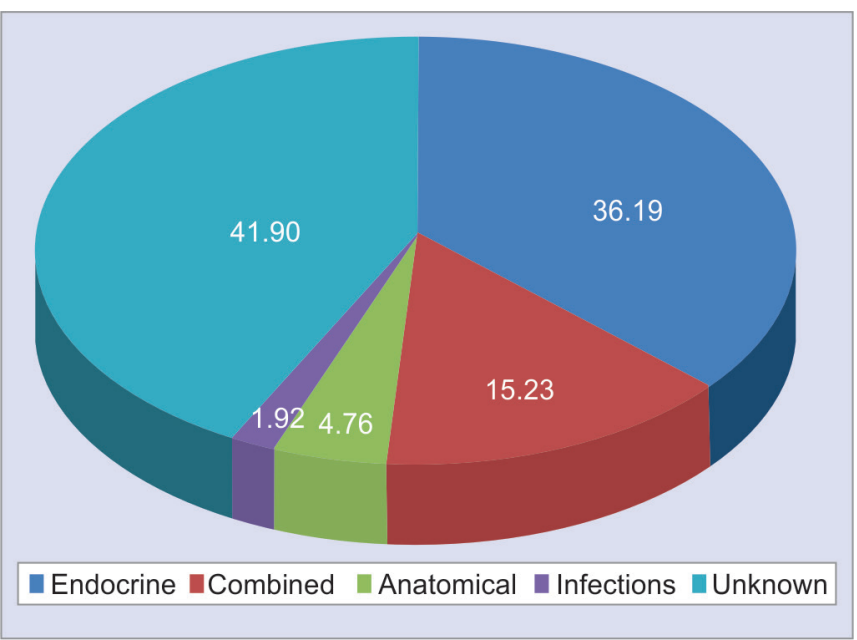

Fig. 1: Etiology of first early pregnancy loss

Table 5: Thrombophilia evaluation for unknown causes in RPL

\begin{tabular}{lllc}
\hline SI. No & Study & Thrombophilia & $\begin{array}{c}\text { Percentage of RPL } \\
\text { women positive (\%) }\end{array}$ \\
\hline 1 & Vora et al. $^{17}$ & Acquired & 46 \\
& & Inherited & 37 \\
2 & Patil et al. $^{18}$ & Acquired & 24 \\
& & Inherited & 16 \\
3 & \multirow{2}{*}{ Present study (2019) } & Acquired & 10.1 \\
& & Inherited & 6.7 \\
& & Combined & 1.69 \\
\hline
\end{tabular}

PAI 4G/3G polymorphisms. ${ }^{17}$ Previous study by Patil et al. in women with unexplained RPL showed that $40 \%$ of RPL women were positive for thrombophilias. ${ }^{18}$ In the present study, we found that $18 \%$ of RPL women were positive for thrombophilias. We could investigate only 103 women of unknown RPL and first pregnancy loss, whereas Vora et al. tested 381 women only with RPL. To come to conclusion regarding the necessity of testing for thrombophilias number needed to test would be 281 with $95 \% \mathrm{Cl}$ when $24 \%$ positivity of thrombophilias as reported by Patil et al. in $2015 .^{18}$

Acquired thrombophilia constituted $10 \%$ and congenital thrombophilia constituted $6.7 \%$, and one woman had both congenital and acquired thrombophilias. The difference in the results might be because we screened only for APLA, protein C, and protein $\mathrm{S}$ as compared to previous studies that screened for more causes of congenital thrombophilias, thus explaining the incidence of thrombophilia being less in the present study. The proportion of women with first pregnancy loss positive for thrombophilia was comparable to women with RPL. There are no previous studies in the literature for thrombophilia evaluation after one miscarriage. As per ESHRE guidelines, ${ }^{3}$ screening for thrombophilia in RPL can be considered, while RCOG ${ }^{19}$ and $\mathrm{ASRM}^{20}$ recommend screening for thrombophilia in RPL women.

\section{Conclusion}

A significant proportion of women (65\%) with first early pregnancy loss had various etiological factors and endocrine factors were the most common causes. Among the identifiable causes for first early pregnancy loss, anatomical factors were found in $4.76 \%$, endocrine in $36 \%$, thrombophilia in $18 \%$, and combined etiology in $15 \%$.

Statistically, significantly more women with first pregnancy loss were found to have known etiological factors when compared to women with RPL. The thrombophilia positivity was found to be similar in both the groups.

Evaluation should be undertaken for women with first early pregnancy loss so that further pregnancy loss can be prevented to achieve optimum pregnancy outcomes. Thrombophilia screening may be undertaken for women when the endocrine causes and anatomical causes are normal.

\section{Limitations of the Study}

Thrombophilia evaluation was done only in women with unknown causes in both the groups. Congenital thrombophilia screening could not be done for all women with unknown causes because of high cost and limited funds.

\section{Clinical Significance}

Evaluation of women with first pregnancy loss helps the clinician to prevent pregnancy loss in subsequent pregnancies by appropriate management as per the etiology.

\section{ACKNOWLEDGMENTS}

The authors acknowledge Dr Subitha L, Associate Professor and Dr Balachandiran V, Junior Resident, Department of Preventive and Social Medicine, JIPMER, Puducherry, India for helping with the statistical analysis.

\section{Authors' Roles}

Papa Dasari conceived the idea and gave the concept for design of the study after reviewing the literature and edited 
the manuscript. Sonal Garg performed the data collection, data analysis, review of the literature, and drafted the manuscript. Rakhee Kar helped in processing the investigations and in their interpretation. Chitra Thyagaraju helped in the recruitment of subjects and reviewed the data. All authors agreed with the contents of the manuscript.

\section{ORCID}

Thyagaraju Chitra ำ https://orcid.org/0000-0002-3224-9180

\section{References}

1. Prager S, Dalton VK, Allen RH. American College of Obstetricians and Gynaecologists. New recommendations on early pregnancy loss-ACOG. 2020. Available from: https://www.acog.org/AboutACOG/News-Room/News-Releases/2015/ACOG-Releases-NewRecommendations-on-Early-Pregnancy-Loss.

2. Wang $X$, Chen C, Wang L, et al. Conception, early pregnancy loss, and time to clinical pregnancy: a population-based prospective study. Fertil Steril 2003;79(3):577-584. DOI: 10.1016/s0015-0282(02)04694-0.

3. Bender Atik R, Christiansen OB, Elson J, et al. ESHRE guideline: recurrent pregnancy loss. Hum Reprod Open 2018;2018:hoy004. DOI: 10.1093/hropen/hoy004.

4. El Hachem H, Crepaux V, May-Panloup P, et al. Recurrent pregnancy loss: current perspectives. Int J Womens Health 2017;9:331-345. DOI: 10.2147/IJWH.S100817.

5. Nynas J, Narang P, Kolikonda MK, et al. Depression and anxiety following early pregnancy loss: recommendations for primary care providers. The primary care companion for CNS disorders 2015;17(1). DOI: $10.4088 /$ pcc.14r01721.

6. Nybo Andersen AM, Wohlfahrt J, Christens P, et al. Maternal age and fetal loss: population based register linkage study. BMJ 2000;320(7251):1708-1712. DOI: 10.1136/bmj.320.7251.1708.

7. Bhandari HM, Tan BK, Quenby S. Superfertility is more prevalent in obese women with recurrent early pregnancy miscarriage. BJOG Int J Obstet Gynaecol 2016;123(2):217-222. DOI: 10.1111/14710528.13806.

8. Matjila MJ, Hoffman A, van der Spuy ZM. Medical conditions associated with recurrent miscarriage - is BMI the tip of the iceberg? Eur J Obstet Gynecol Reprod Biol 2017;214:91-96. DOI: 10.1016/ j.ejogrb.2017.05.003.
9. Cavalcante $M B$, Sarno $M$, Peixoto $A B$, et al. Obesity and recurrent miscarriage: a systematic review and meta-analysis. J Obstet Gynaecol Res 2019;45(1):30-38. DOI: 10.1111/jog.13799.

10. Shetty MB, Malyala $M$, Swarup $A$, et al. Recurrent pregnancy loss: challenge to obstetricians. Int J Reprod Contracept Obstet Gynecol 2017;6(8):3376. DOI: 10.18203/2320-1770.ijrcog20173371.

11. Lee GS, Park JC, Rhee JH, et al. Etiologic characteristics and index pregnancy outcomes of recurrent pregnancy losses in Korean women. Obstet Gynecol Sci 2016;59(5):379-387. DOI: 10.5468/ ogs.2016.59.5.379.

12. Li TC, Spuijbroek MD, Tuckerman E, et al. Endocrinological and endometrial factors in recurrent miscarriage. BJOG Int J Obstet Gynaecol 2000;107(12):1471-1479. DOI: 10.1111/j.1471-0528.2000. tb11670.x.

13. Singh A, Kujur A, Rathore K. An evaluation of recurrent pregnancy loss. Int J Reprod Contracept Obstet Gynecol 2017;6(4):1332. DOI: 10.18203/2320-1770.ijrcog20171387.

14. Cocksedge KA, Li T-C, Saravelos SH, et al. A reappraisal of the role of polycystic ovary syndrome in recurrent miscarriage. Reprod Biomed Online 2008;17(1):151-160. DOI: 10.1016/s1472-6483(10)60304-5.

15. Salim R, Regan L, Woelfer B, et al. A comparative study of the morphology of congenital uterine anomalies in women with and without a history of recurrent first trimester miscarriage. Hum Reprod Oxf Engl 2003;18(1):162-166. DOI: 10.1093/humrep/deg030.

16. Ford HB, Schust DJ. Recurrent pregnancy loss: etiology, diagnosis, and therapy. Rev Obstet Gynecol 2009;2(2):76-83. PMCID: PMC2709325.

17. Vora S, Shetty S, Salvi V, et al. Thrombophilia and unexplained pregnancy loss in Indian patients. Natl Med J India 2008;21(3):116-119. PMID: 19004141.

18. Patil R, Ghosh K, Vora S, et al. Inherited and acquired thrombophilia in Indian women experiencing unexplained recurrent pregnancy loss. Blood Cells Mol Dis 2015;55(3):200-205. DOI: 10.1016/ j.bcmd.2015.06.008.

19. Regan L, Backos M, Rai R Royal College of Obstetricians and Gynecologists. The investigation and treatment of couples with recurrent first-trimester and second-trimester miscarriage Green top guideline number 17. Available from: https://www.rcog.org.uk/ globalassets/documents/guidelines/gtg_17.pdf [Accessed May 20, 2020].

20. Pfeifer S, Fritz M, Goldberg J, et al. Practice Committee of the American Society for Reproductive Medicine. Evaluation and treatment of recurrent pregnancy loss: a committee opinion. Fertil Steril 2012;98(5):1103-1111. DOI: 10.1016/j.fertnstert.2012.06.048. 